ESPAÇO ABERTO

\title{
A participação das crianças nas pesquisas: nuances a partir da etnografia e na investigação participativa
}

\author{
Natália Fernandes' (1) \\ Rita de Cássia Marchil
}

\section{RESUMO}

As conquistas realizadas nas últimas duas décadas sobre a possibilidade de considerar as crianças como sujeitos de pesquisa foram muito significativas e, desse modo, têm-se multiplicado publicações que anunciam a participação da criança no desenvolvimento de investigações. No entanto, o conceito de participação tem sido invocado para dar conta de práticas de pesquisa nas quais, muitas vezes, não está assegurado sequer um nível básico em tomar as vozes das crianças em consideração. Neste texto propomos argumentar pela mobilização crítica desse conceito com base em dois métodos de pesquisa: a etnografia e a investigação participativa. Discutiremos semelhanças e diferenças entre esses métodos, argumentando e interrogando as formas e os significados que a participação das crianças assume em cada um, tendo em conta aspectos epistemológicos e políticos que lhes são inerentes e as implicações que têm na forma como o conceito de participação é mobilizado nos processos de pesquisa.

PALAVRAS-CHAVE

etnografia; investigação participativa; participação; pesquisa com crianças. 


\title{
THE PARTICIPATION OF CHILDREN IN RESEARCH: NUANCES BASED ON ETHNOGRAPHY AND PARTICIPATORY RESEARCH
}

\begin{abstract}
In the last two decades the achievements on the possibility of considering children as active subjects of research have been very significant and, thus, there have been many publications announcing children's participation as the major contribution in its development. However, the concept of participation has been invoked to account for research practices in which, many times, even a basic level in taking children's voices into account is not assured. In this text we propose to argue for the critical mobilization of this concept based on two research methods: ethnography and participatory research. We will discuss similarities and differences between these methods, arguing and questioning the forms and meanings that the participation of children takes in each one, taking into account the epistemological and political aspects that are inherent to them and the implications that they have in how the concept of participation is mobilized in the research processes.
\end{abstract}

\section{KEYWORDS}

ethnography; participatory research; participation; research with children.

\section{LA PARTICIPACIÓN DE LOS NIÑOS EN LA INVESTIGACIÓN: NUANCES DE LA ETNOGRAFÍA Y LA INVESTIGACIÓN PARTICIPATIVA}

\section{RESUMEN}

Los logros alcanzados en las últimas dos décadas sobre la posibilidad de considerar a los niños como sujetos de investigación han sido muy significativos y, por lo tanto, ha habido una multiplicación de publicaciones que anuncian la participación del niño en el desarrollo de las investigaciones. Sin embargo, se ha invocado el concepto de participación para dar cuenta de las prácticas de investigación en las que, muchas veces, incluso un nivel básico para tener en cuenta las voces de los niños no está asegurado. En este texto proponemos defender la movilización crítica de este concepto utilizando dos métodos de investigación: etnografía e investigación participativa. Discutiremos las similitudes y diferencias entre estos métodos, discutiendo y cuestionando las formas y los significados que la participación de los niños toma en cada uno, teniendo en cuenta los aspectos epistemológicos y políticos que son inherentes a ellos y las implicaciones que tienen en cómo es el concepto de participación. movilizado en los procesos de investigación.

PALABRAS CLAVE

etnografía; investigación participativa; participación; investigación con niños. 


\section{INVESTIGAÇÃO COM CRIANÇAS}

Assumir as crianças como atores sociais, ou seja, como sujeitos ativos de direitos com ação socialmente relevante, tem se mostrado, após a promulgação da Convenção das Nações Unidas sobre os Direitos da Criança (1989), um movimento crescente.

Decorrente desse impulso, a partir de fins da década de 1980, paulatinamente consolidam-se abordagens teóricas que partilham de um mesmo pressuposto: o de que as crianças têm um papel central nos processos de construção de conhecimento acerca de si, o que exige um olhar mais denso e cuidadoso sobre os métodos de pesquisa e sobre a ética nas relações desenvolvidas nos enfoques investigativos mobilizados.

Com argumentos que se consolidaram no campo acadêmico, esse percurso parece ter caminhado de uma quase invisibilidade das crianças como objetos ou sujeitos de pesquisa para a sua centralidade, sendo seus direitos de provisão, de proteção e de participação mobilizados de forma interconectada nesse processo.

As crianças passam, assim, a ser consideradas sujeitos legitimos do conhecimento (authoritative knowers), em um movimento que vai desenvolvendo novas perspectivas metodológicas acerca da pesquisa sobre e com crianças, além de diferentes exigências éticas nas relações de investigação. Tal fato implica que o investigador deverá mobilizar a sua imaginação objetivando conceber aproximações metodológicas que respeitem a alteridade das crianças: seus tempos, suas agendas, suas linguagens; significa, ainda, que esse investigador deverá mobilizar um comprometimento ético apurado para convocar de forma respeitosa as vozes das crianças, sem as deixar subsumidas na voz do adulto que as interpreta.

$\mathrm{Na}$ sequência dessa ideia, Kallio e Häkli (2011) defendem que considerar as crianças como membros ativos de suas comunidades e sociedades, e não meros objetos de processos socializadores top-down, exige que se revejam posicionamentos ontológicos e epistemológicos, isso logo no que diz respeito à dimensão política da ação das crianças e, acrescentaríamos nós, da sua participação política na pesquisa.

Os argumentos políticos e éticos acerca dos direitos da criança a essa participação estão muitas vezes aliados a discursos sobre vantagens epistemológicas. Kesby (2000) defende que tal participação permite produzir conhecimento mais autêntico acerca das realidades subjetivas das crianças, ideia que se baseia na premissa de que a identidade produz conhecimento, ou seja, as pessoas, no caso as crianças, estão em melhor posição para produzir conhecimento acerca de si e dos seus pares.

Assim, mobilizar processos de pesquisa que considerem as crianças como sujeitos de direitos tem, de acordo com Lundy e McEvoy (2011), significativas implicações para essas pesquisas, defendendo as autoras que

[...] quando as crianças são vistas como titulares de direitos, não são somente reconhecidas como sendo capazes, mas também como tendo o direito de estar envolvidas nesses processos, com o concomitante dever dos adultos de assegurar que seu direito de expressar suas perspectivas e influenciar sua vida seja respeitado. (Lundy e McEvoy, 2011, p. 130, tradução nossa) 
Uma focalização, portanto, não somente na salvaguarda de contextos inclusivos de proteção e segurança, mas também em estratégias que garantam às crianças a possibilidade de expressar seus pontos de vista e de os mobilizar na discussão para tomadas de decisão, é uma exigência fulcral, que vai marcar os modos de desenvolver pesquisa com crianças na atualidade.

\section{PARTICIPAÇÃO DAS CRIANÇAS NAS PESQUISAS}

A academia tem dedicado uma atenção significativa à conceitualização da participação das crianças nas pesquisas, com significativos desenvolvimentos nesse sentido, afirmando Aitken e Millar (2002) que assistimos a uma "cultura da consulta", nas últimas duas décadas. Desde a criança observada, a criança entrevistada ou, ainda, a criança pesquisadora, múltiplas e diversas são as formas de conceber essa participação, sendo talvez a imagem da criança como pesquisador ou copesquisador (Alderson, 2005) a mais improvável e menos frequente nas possibilidades de envolvimento desses atores sociais no processo.

Esse é um tema que tem ocupado as reflexões, nomeadamente, na literatura lusófona. Consideramos, a esse propósito, o trabalho desenvolvido por Prado (2014), que teve o objetivo de investigar como tem sido considerada a participação das crianças em pesquisas no Brasil. ${ }^{1}$ Essa autora afirma que, em larga medida, a escuta das crianças nas pesquisas restringe-se aos estudos no âmbito da psicologia e, em menor grau, da educação, sendo raros artigos de antropólogos ou sociólogos que relatam o envolvimento de crianças nas investigações. Assim, a pesquisadora conclui que o contexto brasileiro difere do âmbito internacional, em que sociólogos e antropólogos ocupam, nas últimas décadas, posições de relevo no que diz respeito à visibilidade das crianças nas pesquisas e à abertura de espaços para a escuta de suas vozes e participação.

No citado trabalho, é ainda destacado que nos estudos brasileiros predomina a perspectiva da criança como sujeito, sendo nos artigos da área da pedagogia que as ideias da criança como ator social e como participante estão mais representadas. Mas a autora destaca também que, embora minoria, ainda existem estudos em que a criança é "vista como objeto, herança, provável, da psicometria e de correntes como o behaviorismo" (Prado, 2014, p. 190-191).

Nesse percurso, é de realçar também o contributo crítico de alguns dos autores de referência da sociologia anglo-saxônica, que se têm debruçado criticamente sobre os processos de pesquisa com crianças, olhando mais densamente para os modos como alguns conceitos mais frequentes são utlizados, como é o caso do conceito voz da criança. A esse propósito, Allison James defende, em 2007, no texto Giving voice to children's voices: practices and problems, pitfalls and potencials, que

1 As áreas de conhecimento consideradas na pesquisa foram antropologia, sociologia, psicologia e pedagogia (educação). 
dar voz às crianças não significa simplesmente deixá-las falar. Trata-se de explorar o contributo único que isso oferece para a compreensão e a teorização acerca do mundo social. (James, 2007, p. 262, tradução nossa)

A partir desse desafio, a autora exorta-nos a pensar no significado atribuído às vozes das crianças, considerando-se três fatores: autenticidade, diversidade e natureza da participação.

No que diz respeito às questões da autenticidade, James (2007) refere a importância de considerarmos que nos processos de pesquisa podem levantar-se problemas de tradução, interpretação e mediação diante das estratégias utilizadas para ouvir as vozes das crianças. Refere essa autora que devemos, necessariamente, desenvolver uma reflexividade que nos auxilie a pensar em processos de pesquisa $\mathrm{e}$ modos de respeitar essas vozes, salvaguardando o fato de que, apesar de serem os adultos que escrevem os relatórios de pesquisa, estes o devem fazer de modo que não deturpaem os pontos de vista das crianças.

Apesar de as palavras das crianças, que aparecem nos relatórios, poderem ser apresentadas como autênticas, coloca-se o caso de as palavras ou frases serem escolhidas pelo pesquisador e inseridas no texto para ilustrar um argumento ou sublinhar um ponto de vista do pesquisador. (James, 2007, p. 265 , tradução nossa)

Essa exigência deve ser mobilizada também nos contextos culturais de produção das vozes das crianças, isto é, "as vozes das crianças que incluímos nos nossos textos devem ser compreendidas nas suas particularidades. A sua autenticidade deve ser interrogada, e não assumida" (James, 2007, p. 265, tradução nossa). Deve ser interrogado, assim, em nossa opinião, o modo como se constrói a relação de pesquisa entre adultos e crianças, o modo como se salvaguardam as questões de poder e, finalmente, o modo como se criam condições para que a autenticidade se possa exprimir e não ficar oculta ou refém da impossibilidade de a criança se assumir como sujeito, como ator no processo de construção do conhecimento.

A conceitualização voz da criança é uma categoria usada, muitas vezes, para falar de uma voz indiferenciada, independentemente de classe social ou cultura, o que, portanto, esconde também a questão da diversidade. O risco é quando não se acautela o contexto de produção dessa voz, ou seja, quando não se acautelam as condições adequadas para que a criança, em sua diversidade existencial, possa falar, salvaguardando que sua voz não seja apenas eco de algumas, porventura aquelas mais expressivas, que detêm mais poder ou maior protagonismo nas relações de pares e com os adultos. Desse modo, em vez de se atribuir à criança, a todas as crianças, visibilidade ou audiência como ator social, alimenta-se uma retórica vazia de diversidade, vazia de significado, que deturpa o conceito de voz plural e diversa, que não resgata as experiências únicas de cada criança em sua individualidade e enquanto sujeito pertencente ao espaço geracional coletivo que é a infância. 
O questionamento da natureza da participação das crianças no processo de pesquisa é o terceiro aspecto identificado por James (2007). A autora afirma que a maneira como os estudos da criança se foram desenvolvendo está alicerçada no pressuposto que concebe que a pesquisa deve ser compreendida como um processo realizado com as crianças e não nas crianças, sendo a sua participação nesse processo uma inferência básica.

Mas será que todos falamos da mesma coisa, quando falamos da participação das crianças nas pesquisas?

Concebemos, neste texto, o conceito de participação com base na proposta de Percy-Smith e Malone (2001, p. 18, tradução nossa), quando os autores referem que

participação autêntica envolve a inclusão - em que o sistema se altera para acomodar a participação e os valores das crianças - em vez de integração em que as crianças participam de formas predefinidas em estruturas predefinidas. É por meio desses argumentos que a nossa teorização acerca da participação das crianças necessita ser encaminhada, se queremos celebrar e valorizar o papel das crianças como participantes tanto em nossos projetos como em seu próprio direito.

Nessa sequência, quando se defende, em termos epistemológicos e metodológicos, a participação da criança em pesquisas, deve-se ter presente a necessidade de abrir possibilidades de ela desenvolver um papel influente no processo.

Assim, parece-nos interessante convocar as propostas de Lundy (2007), quando refere que será necessário considerar, nas dinâmicas participativas, aspectos como o espaço, a voz, a audiência e a influência. Espaço, no sentido de que a criança deve ter acesso a oportunidades seguras e inclusivas para formar e expressar seus pontos de vista. Voz, no sentido de que devem ser criadas condições para que a criança possa expressar-se valorizando para tal suas diferentes formas de comunicação. Audiência, no sentido em que as opiniões da criança deve encontrar espaços e tempos de escuta significativa. Finalmente, influência, no sentido de que suas opiniões devem ser acolhidas de forma séria no processo de tomada de decisão.

Considerando essas quatro dimensões, agora em referência aos processos de pesquisa, facilmente percebemos que muito dificilmente se consegue acautelar a totalidade desses aspectos e, particularmente, o último, relativo à influência. Retomaremos mais adiante essa questão, quando nos ocuparmos dos dois métodos de pesquisa que tomaremos em consideração neste texto.

Para remate desta parte da discussão, consideramos ainda importante sublinhar que são distintas as questões relativas ao desenvolvimento da problematização da participação das crianças em pesquisas e que as dimensões ontológicas e políticas que influenciam os métodos de pesquisa, as quais lhes atribuem posicionamentos metodológicos diferenciados, deverão ser alvo de maior análise e atenção, de modo que não deturpem um conceito fundacional para os estudos da criança, como é o conceito aqui debatido de participação de crianças em pesquisa, tal como refere Roberts (2000, p. 238, tradução nossa) ao afirmar que 
as razões por que uma criança ou jovem devam escolher participar em uma pesquisa são mais claros em alguns estudos do que em outros... não podemos assumir que a participação em pesquisa e o desenvolvimento crescente de métodos de pesquisa altamente sofisticados para facilitar a participação da criança são necessariamente desenvolvidos em seu melhor interesse.

Assim, o que pretendemos neste texto é mobilizar, de forma crítica, o conceito de participação com baise em dois métodos de pesquisa: a etnografia e a investigação participativa. Serão discutidas suas semelhanças e diferenças, argumentando e interrogando as formas e os significados que esse conceito assume em cada um, tendo em conta aspectos epistemológicos e políticos que lhes são inerentes e as implicações que têm na forma como o conceito de participação é mobilizado nos processos de pesquisa com crianças.

\section{PESQUISA ETNOGRÁFICA E PESQUISA PARTICIPATIVA: DISCUTINDO A PARTICIPAÇÃO DAS CRIANÇAS}

Neste subitem vamos tratar das características que conformam dois diferentes métodos de pesquisa: a etnografia e a investigação participativa. Portanto, tentaremos estabelecer as nuances ontológicas e epistemológicas, além dos princípios e das consequências políticas desses métodos, notadamente no que diz respeito aos modos como a participação das crianças é neles concebida e mobilizada pelos pesquisadores.

Para isso, de início, vamos nos referir ao que Sarmento e Marchi (2008) esclarecem, de forma esquemática, sobre o fato de a sociologia da infância poder ser apresentada por três grandes correntes sociológicas: a estrutural; a interpretativa; e os estudos ancorados na perspectiva crítica. A distinção entre essas correntes corresponde, grosso modo, aos paradigmas clássicos da sociologia e a três de seus conceitos-chave: estrutura, ação social e praxis. ${ }^{2}$

Para os objetivos deste artigo, vamos nos limitar a pontuar, respectivamente, a metodologia etnográfica e a investigação participativa no quadro das duas últimas correntes.

$\mathrm{Na}$ corrente interpretativa, os trabalhos empíricos são constituídos predominantemente por estudos etnográficos, visto que em tal vertente esses estudos são considerados particularmente úteis para o conhecimento da infância e das crianças (James e Prout, 1990). A corrente crítica, por seu lado, defende que a sociologia da infância só consumará suas finalidades se contribuir para a emancipação social da infância; assim, a vinculação do trabalho investigativo e analítico às formas de intervenção é feito tanto por meio de estudos aplicados quanto, de modo indireto,

2 No entanto, a sociologia da infância, como a própria sociologia, tem enfrentado o desafio de articular - no plano teórico e conceitual - a dicotomia presente nesses conceitos clássicos, para a tarefa da compreensão contemporânea da complexidade e ambiguidade da infância como categoria conceitualmente autônoma (Prout, 2005; Sarmento e Marchi, 2008). 
em programas políticos, decorrendo daí a opção por estudos de "investigação-ação" ou da "investigação participativa" (Sarmento e Marchi, 2008).

Uma vez que a vertente interpretativa da sociologia da infância recomendou os métodos etnográficos (provenientes da antropologia) como particularmente úteis para o estudo da infância, muito se tem discutido sobre essa metodologia e o seu uso, especialmente na área da educação. Assim, alguns autores, diante do que já consideram uma vulgarização ou moda metodológica, têm se dedicado a analisar os resultados problemáticos da apropriação ou transposição apenas instrumental ou tópica da etnografia para as pesquisas em educação. Esses autores sinalizam que grande parte dos estudos nessa área realiza uma inadequada ou duvidosa apropriação/transposição do método, desconhece os princípios básicos da etnografia, apresenta ausência de base teórica ou falta de clareza sobre o papel da teoria na pesquisa e o pouco tempo de trabalho de campo realizado (Marchi, 2018; Mattos, 2011; Tosta, 2008).

Outros autores, no entanto, têm se dedicado a debater as caraterísticas da etnografia com/sobre crianças, refletindo sobre questões de caráter epistemológico, teórico, metodológico e ético no que concerne ao desenvolvimento desse tipo de pesquisa. ${ }^{3}$ Esses debatedores costumam se referir às diferentes estratégias a serem utilizadas pelos pesquisadores conforme a faixa etária das crianças (bebês, crianças pequenas, em idade escolar etc.) e também o contexto/local da pesquisa (creche, escola, casa, rua etc.). Tais estratégias, consideradas as variáveis mencionadas, dizem mais frequentemente respeito aos modos de entrada e aceitação do pesquisador no campo, à obtenção do consentimento e/ou assentimento por parte das crianças em participar da pesquisa, às dificuldades e desafios para a geração dos dados, assim como as diferentes técnicas para os obter com fidedignidade e dentro de parâmetros éticos.

Três aspectos, no entanto, podem ser apontados como distintivos e recorrentes nessa literatura: o da participação e consideração das vozes infantis, a questão do combate ao adultocentrismo e a questão ética. São três aspectos que estão intrinsicamente relacionados e que trazem em seu cerne os desafios centrais à pesquisa etnográfica com crianças.

Em relação à consideração das vozes infantis, deve-se considerar que o surgimento de novas formas de fazer etnografia — que são hoje denominadas reflexivas, ${ }^{4}$ dialógicas ou polifônicas - surgiu da crítica realizada nos anos 80 do século XX ao modelo clássico da autoridade etnográfica.

3 Entre esses autores, podemos citar Manuel Sarmento, William Corsaro, Manuela Ferreira, Julie Delalande, Ana Coll Delgado, entre os mais proeminentes nessa discussão. Há autores que também sinalizam uma abordagem com métodos mistos para o estudo com crianças, combinando a etnografia com tecnologias digitais para o acesso às suas vozes e cotidiano (Christensen et al., 2014).

4 Reflexiva porque considera a necessidade de o pesquisador pensar a si mesmo na relação de pesquisa, que implica sempre uma relação de desigualdade e poder e, no caso de pesquisas com/sobre crianças, é acrescida da diferença e do poder geracional. 
A discussão central (e principal mudança ocorrida) se deu em torno da questão da "voz": quem e de onde se fala. Essa reflexão sobre a relação de poder entre pesquisador e pesquisado e a inclusão das diversas vozes (polifonia) presentes no campo da pesquisa incidiu diretamente sobre as pesquisas etnográficas realizadas com crianças a partir da década de 90 do século XX. Importante notar que a mudança na nomenclatura - de pesquisa sobre se passa à pesquisa com crianças - já indica a nova disposição ou orientação dos pesquisadores em direção à participação das crianças no processo da investigação. (Marchi, 2018, p. 728 , grifo nosso)

Necessário também destacar que, como argumentam Marchi (2018) e outros (Fernandes, 2016; Ferreira, 2010; Roberts, 2000; Spyrou, 2011), dar voz aos sujeitos da pesquisa não significa mais falar em seu nome, como no modelo monológico das etnografias clássicas. Ou seja, não se trata mais de subsumir a voz do(s) outro(s) à voz do pesquisador e do seu arcabouço teórico, por mais bem-intencionada politicamente falando - que essa voz possa ser ou estar. Portanto, a questão da consideração das vozes infantis tem por duplo registro o fim da monologia (derivada da crítica ao etnocentrismo da autoridade etnográfica) e a garantia da escuta e participação das crianças nas pesquisas. Importante salientar que essa participação é, no entanto, concebida mais no nível da consulta (Aitken e Millar, 2002), isto é, o desenho da pesquisa (objetivos, técnicas de geração de dados, delimitação do campo e dos sujeitos da investigação), assim como a análise e a interpretação dos dados ficam centralizados no pesquisador, ainda que este leve em consideração as vozes das crianças. Assim, trata-se de uma participação limitada ou de limitado alcance, embora o princípio político da consideração das vozes das crianças esteja presente nas ações, intenções e disposições do pesquisador como importante passo no combate ao adultocentrismo.

O problema do adultocentrismo pode ser visto como equivalente ao do etnocentrismo, que, como visto anteriormente, gerou a forte crítica ao modelo clássico da autoridade etnográfica nos anos de 1980, mudando de forma definitiva a maneira de se fazer etnografia. Assim, a crítica ao adultocentrismo nas pesquisas etnográficas com crianças segue a mesma lógica relativizadora, mas tendo por base a questão geracional do poder adulto.

Por fim, a questão ética, pode-se dizer, enlaça de maneira incontornável as duas outras questões, fazendo com que nenhum desses apectos possa ser metodologicamente bem conduzido sem a boa resolução do outro. Uma discussão central relativa à ética na pesquisa com crianças diz respeito ao fato de que, para além dos princípios éticos a serem respeitados e seguidos, qualquer que seja a idade e demais características pessoais e identitárias dos sujeitos alvo da investigação, os pesquisadores precisam também levar em conta especificidades relativas ao grupo geracional das crianças. Nesse sentido, instala-se de maneira muito particular a tensão entre os chamados direitos de liberdade e participação e os direitos de proteção, presentes de forma original na Convenção Internacional sobre os Direitos das Crianças, de 1989. Tensão esta que não pode ser resolvida de modo unilateral, devendo os pesquisadores atentarem para o fato de que 
[...] não há uma ética à la carte passível de ser replicada em cada contexto, mas sim que as relações éticas são portadoras de diversidade e complexidade e exigem um cuidado ontológico permanente de construção e reconstrução, porque a ética está ligada à construção ativa de relações de investigação e não pode ser baseada em pressupostos ou estereótipos acerca das crianças e da infância - depende, afinal, da consideração da alteridade que configura a infância. (Fernandes, 2016, p. 763)

No caso das investigações etnográficas com crianças, tem-se por pressuposto que esse grupo geracional produz as chamadas culturas infantis e, assim, o método etnográfico é aquele que, por excelência, permite conhecer e interpretar as formas coletivas como os grupos ou tribos infantis se formam, se organizam, se diluem ou se mantêm unidos por regras, princípios e rituais próprios. Realizar uma etnografia com crianças significa, portanto, compreender que significado(s) as suas ações têm no sistema simbólico das culturas infantis (Marchi, 2018). E, para, além disso, de que forma os fatos ou os atos observados no âmbito dessas culturas se relacionam e se inscrevem no quadro amplo da cultura dos adultos, isto é, da sociedade como um todo, já que as crianças estão sempre integrando e participando desses dois registros culturais complexamente interligados: as culturas infantis e a cultura dos adultos (Corsaro, 2011).

Parece-nos evidente que a participação de uma criança em uma pesquisa etnográfica, na qual é objeto do olhar do investigador, não tem a mesma natureza que assume em um processo de investigação participativa, em que ela é parceira nas tomadas de decisão acerca do alinhamento e do desenvolvimento do processo investigativo.

Em contraste, a investigação participativa carateriza-se por especificidades ontológicas e epistemológicas que lhe conferem, necessariamente, uma natureza distinta de outras possibilidades metodológicas, nomeadamente a etnografia, por se basear na ideia da

conquista de uma participação democrática e justiça social para as crianças. Ao influenciarem o que está a ser investigado, e a forma como as suas vidas são representadas, elas participam em processos institucionais de tomada de decisão. Quanto mais as crianças forem activamente envolvidas na investigação, maiores serão os ganhos a nível pessoal. (Kirby, 1999, p. 1, tradução nossa)

A investigação participativa com crianças sustenta-se com base no paradigma participativo (Lincoln e Guba, 2001), que se apresenta como uma nova possibilidade de entender a investigação como uma realidade participada (Heron e Reason, 1997). Esse paradigma, surgindo como uma crítica a outros mais positivistas e funcionalistas, vai, também, além do que o paradigma construtivista/ interpretativo propõe, ou seja, no paradigma participativo interessa ir para além da compreensão da realidade social. Ele encontra afinidades eletivas no paradigma crítico identificado por Sarmento e Marchi (2008), uma vez que pugna por uma ciência implicada e transformadora. O paradigma crítico da sociologia da infância 
ajuda a sustentar epistemologicamente o modo de conceber pesquisa a que nos mobiliza o paradigma participativo. Interessa, sobretudo, assumir que o modo de produção de conhecimento é feito apoiados em quadros sócio-históricos dialéticos, alterando-se os tradicionais papéis de investigadores e participantes da pesquisa, valorizando-se, sobretudo, uma relação sujeito-sujeito, na qual a criança assume um papel tão ou mais importante que o do adulto-investigador.

A investigação participativa exige, de acordo com Alderson (2005), uma mobilização de atores com papéis distintos, mas complementares, sendo que adultos e crianças necessitam implicar-se em práticas reiteradas de cooperação e negociação.

Assim, enquanto na investigação etnográfica as ações das crianças são observadas e interpretadas, na investigação participativa a criança assume um papel ativo na observação, na descrição, na interpretação, agindo, assumindo-se como um sujeito, com um papel ativo e transformador do processo de pesquisa, sendo a sua voz e a sua ação social aspectos centrais para o processo de desenvolvimento das dinâmicas da investigação. A esse propósito, Santana e Fernandes (2011, p. 13) afirmam:

se, por um lado, os dados construídos numa pesquisa participativa parecem retratar de forma mais fidedigna a realidade das crianças, por outro, possibilitam que elas desenvolvam competências que alteram a sua forma de interação com o meio em que vivem.

O método da investigação participativa com crianças distingue-se, assim, de outras possibilidades metodológicas de construção de conhecimento ao defender um conhecimento implicado e crítico das práticas sociais, sendo as crianças os seus principais atores e autores.

Os desafios que resultam da opção por essa possibilidade metodológica de construção de conhecimento são significativos. De início, requer que o pesquisador repense o papel tradicional que lhe estava adstrito enquanto responsável e coordenador de todas as etapas do processo de investigação. Requer, ainda, que considere que deverá partilhar seu poder com o outro criança, que assume protagonismo no processo e vai partilhar com o pesquisador a tomada de decisão acerca do modo como a pesquisa se desenvolve. São, assim, privilegiados processos "em aberto" em detrimento de técnicas predefinidas, o que significa "pensar numa subjectividade emergente, onde se enfatizam processos mais do que produtos. Por isso não podemos reduzir estes processos a regras e técnicas previamente e estritamente estabelecidas" (Gallacher e Gallagher, 2008, p. 500, tradução nossa).

Há de se ter subjacente dimensões mais densas, como as de ordem ontológica e política, que deverão ser cuidadosamente mobilizadas e respeitadas. Nesse sentido, a relação de pesquisa que se vai construindo entre adultos e crianças deve ser reveladora de relações de negociação e parceria, de tomada de decisão conjunta, devedoras de imagens bem definidas da criança como sujeito ativo e político, com um papel central na construção de todo o processo da pesquisa.

A opção pelo desenvolvimento de investigações nas quais as crianças sejam consideradas atores, nas quais sua participação seja condição básica para o andamento da pesquisa, necessita, da parte do pesquisador, de cuidados acrescidos, então 
relacionados com o seu próprio papel no processo e no modo como constrói a relação de investigação com as crianças, acautelando as relações de poder entre ambos e as implicações que estas poderão ter no desvirtuamento do processo; necessita ainda de cuidar das questões éticas de uma forma bastante mais complexa do que em outros modos de construção de conhecimento, dado que a relação de pesquisa necessita ser "vigiada" para que os imprevistos e os improváveis que naturalmente se colocam em dinâmicas participativas não afrontem princípios éticos, como os que dizem respeito à salvaguarda da não exclusão e à proteção contra o dano, entre outros aspectos.

\section{CONSIDERAÇÕES FINAIS}

Finalizando este artigo, queremos destacar que nele não se teve a intenção de atribuir superioridade, seja metodológica ou ética, a este ou àquele método, mas mobilizar, de modo crítico e reflexivo, o conceito de participação nas pesquisas realizadas com crianças, apresentando e interrogando os modos e os significados que esse conceito pode assumir nos processos de investigação.

Assim, orientamos a discussão tomando para análise dois tipos de pesquisa, a etnografia e a investigação participativa, discutindo suas aproximações, distanciamentos e nuances ontológicos, epistemológicos e políticos.

O que nos preocupa, em princípio, é o modo não reflexivo como o conceito de participação das crianças tem sido utilizado em pesquisas, nas quais, muitas vezes, não está sequer assegurado que suas vozes estejam sendo consideradas.

Recuando duas décadas, os precursores dos processos de pesquisa com crianças tinham como preocupação básica salvaguardar a visibilidade das crianças nas pesquisas sobre assuntos que lhes diziam respeito. Para tal, originalmente, os métodos de pesquisa mais comuns foram a etnografia e o estudo de caso. A sua utilização valorizava a questão da voz e da visibilidade da criança em quadros interpretativos, nos quais a preocupação era acentuadamente o registro e a visibilidade da opinião da criança na construção do conhecimento acerca de si e de seus pares.

Com o desenvolvimento das discussões sobre o significado de voz e de ação social da criança, começam a surgir novas propostas metodológicas, nas quais se pretende ir além da interpretação das vozes das crianças e se propõe que a sua imagem enquanto ator social ganhe uma expressão mais implicada. Nesse sentido, trata-se, como já mencionado, não somente da salvaguarda de contextos inclusivos de proteção e segurança, mas também da criação e do desenvolvimento de estratégias metodológicas que possibilitem que as crianças expressem seus pontos de vista e que os mobilizem nas pesquisas com vista a tomadas de decisão e, ainda, que eles sejam respeitados e considerados pelo pesquisador.

É assim que consideramos que a etnografia e a investigação participativa, enquanto métodos de pesquisa com crianças, possuem dimensões políticas e ontológicas diferenciadas, tendo a participação, portanto, também natureza diferenciada em cada um.

O investigador precisa definir claramente, na questão de investigação, suas intenções. Se sua intenção é a de compreender algo com a criança (etnografia), o 
tipo de relação que deve ser estabelecida com ela baseia-se em um conjunto de estratégias/dinâmicas que o investigador inicialmente define, as quais obviamente poderão ser reconsideradas, mas muito pouco negociadas e reorientadas pelas crianças. O nível de participação de que aqui falamos situa-se no nível da consulta.

O mesmo não acontecerá se a intenção do investigador for a de envolver a criança em dinâmicas de pesquisa que pretendem ir além da interpretação e que também já considerem a transformação (investigação participativa). Nesse processo, a criança é um ator principal na definição do andamento da pesquisa. E isso mobiliza o pesquisador a considerar dinâmicas inclusivas que deem espaço e tempo à criança para se apropriar do processo de investigação e para o reinventar à sua medida.

Importante, assim, destacarmos que nesse processo é fulcral repensar o papel dos investigadores em dois sentidos fundamentais e entrelaçados: a transparência ou a clareza na enunciação das intenções de pesquisa e da metodologia adotada, de modo que defina claramente o tipo (ou natureza) da participação desejada ou permitida às crianças.

Nesse sentido, podemos considerar uma maior ou menor abertura ou flexibilidade dos pressupostos metodológicos e técnicas de pesquisa envolvidos, na direção (ou não) de uma possível negociação e reorientação desses elementos pelas crianças. Segundo, o papel do pesquisador na partilha das relações de poder que envolvem as relações intergeracionais e, de modo particular, as relações de pesquisa. Portanto, percebe-se aqui, de maneira mais evidente, o caráter político da ação investigativa. As escolhas feitas pelo pesquisador possibilitarão a emergência ou não de uma subjetividade em que os processos (abertos ou flexíveis) importam mais que os resultados, pois o ganho estará na possibilidade de ativar a contribuição peculiar que as crianças podem dar à compreensão e à teorização do mundo social que (nos)as envolve. Por isso é que somos convidados a pensar os significados das vozes das crianças nas pesquisas considerando os quesitos destacados neste artigo: a autenticidade, a diversidade e a natureza da sua participação.

Finalizamos esta reflexão crítica sobre os modos de produção de conhecimento com as crianças mediante abordagens metodológicas distintas, acentuando a necessidade de um olhar atento acerca da maneira como se mobiliza o conceito de participação. Para tal, consideramos, assim como defendem Gallacher e Gallagher (2008), que o importante nos processos de pesquisa não é tanto os tipos das dinâmicas adotadas, pois uma boa prática de pesquisa não se reduz a técnicas engenhosas (previamente planejadas e cuidadosamente aplicadas), mas à adoção de uma atitude de prudência metodológica.

Pesquisas responsáveis e comprometidas eticamente com os sujeitos nela envolvidos são devedoras da atitude metodológica escolhida, ou seja, dos pressupostos ontológicos, epistemológicos e éticos que estão na base das opções que os pesquisadores fazem. Sendo coerentes com estes, seremos coerentes com todo o roteiro metodológico que mobilizamos, com os sujeitos que envolvemos e com o tipo de ação que eles serão chamados a assumir no processo da pesquisa. A adoção de uma ação mais delegada ou mais ativa da parte das crianças terá sempre lugar nos modos de produção de conhecimento. Terá sempre a sua legitimidade. Terá sempre a sua importância. É ônus do investigador, de forma crítica, assumir e explicitar que 
tipo de ação, afinal, é mobilizada nos processos de investigação desencadeados. Que tipo de imagem de infância e criança enformam suas opções metodológicas? E de que modo e de onde falam, afinal, as crianças em sua pesquisa?

\section{REFERÊNCIAS}

AITKEN, S.; MILLAR, S. Listening to children with communication support needs. Glasgow: Sense Scotland, 2002.

ALDERSON, P. As crianças como pesquisadoras: os efeitos dos direitos de participação sobre a metodologia de pesquisa. Educação \& Sociedade, Campinas, v. 26, n. 91, p. 419-442, maio/ago. 2005. https://doi.org/10.1590/S0101-73302005000200007

CHRISTENSEN, P. et al.Mobilidades cotidianas das crianças: combinando etnografia, GPS e tecnologias de telefone móvel em pesquisa. Educação \& Sociedade, Campinas, v. 35, n. 128, p.699-716, jul./set. 2014. https://doi.org/10.1590/ES0101-73302014128646 CORSARO, W. A. Sociologia da infância. 2. ed. Porto Alegre: Artmed, 2011.

FERNANDES, N. Ética na pesquisa com crianças: ausências e desafios. Revista Brasileira de Educação, Rio de Janeiro, v. 21, n. 66, p. 759-779, jul./set. 2016. https:// doi.org/10.1590/S1413-24782016216639

FERREIRA, M. “- Ela é a nossa prisioneira!” Questões teóricas, epistemológicas e ético-metodológicas a propósito dos processos de obtenção da permissão das crianças pequenas numa pesquisa etnográfica. Reflexão e Ação, Santa Cruz do Sul, v. 18, n. 2, p. 151-182, jul./dez. 2010. https://doi.org/10.17058/rea.v18i2.1524

GALLACHER, L. A.; GALLAGHER, M. Methodological immaturity in childhood research!: thinking through "participatory methods". Childhood, Thousand Oaks, v. 15, n. 4, p. 499-516, 2008. https://doi.org/10.1177/0907568208091672

HERON, J.; REASON, P. A participatory inquiry paradigm. Qualitative Inquiry, Thousand Oaks,v.3,n.3,p.274-294,1997.https://doi.org/10.1177/107780049700300302

JAMES, A. Giving voice to children's voices: practices and problems, pitfalls and potentials. American Anthropologist, New York, v. 109, n. 2, p. 261-272, 2007. https:// doi.org/10.1525/AA.2007.109.2.261

JAMES, A.; PROUT, A. Constructing and reconstructing childhood: contemporary issues in the sociological study of childhood. London: Falmer Press, 1990.

KALLIO, K.; P; HÄKLI, J. Are there politics in childhood? Space and Polity, United Kingdom, v. 15, n. 1, p. 21-34, 2011. https://doi.org/10.1080/13562576.2011.567897 KESBY, M. Participatory diagramming: deploying qualitative methods through an action research epistemology. Area, Royal Geographical Society, v. 32, p. 423-435, 2000. KIRBY, P. Involving young researchers: how to enable young people to design and conduct research. York: The Joseph Rowntree Foundation, 1999.

LINCOLN, Y. S.; GUBA, E. G. Paradigmatic controversies/contradictions/and emerging confluences. In: DENZIN, N. K.; LINCOLN, Y. S. (orgs.). Handbook of qualitative research. 2. ed. London: Sage, 2001. p. 191-215. 
LUNDY, L. "Voice" is not enough: conceptualising article 12 of the United Nations Convention on the Rights of the Child. British Educational Research Journal, United Kingdom, v. 33, n. 6, p. 927-942, 2007. https://doi.org/10.1080/01411920701657033 LUNDY, L.; MCEVOY, L. Children's rights and research processes: assisting children to (in)formed views. Childhood, Thousand Oaks, v. 19, n. 1, p. 129-144, 2011. https:// doi.org/10.1177/0907568211409078

MARCHI, R. C. Pesquisa etnográfica com crianças: participação, voz e ética. Educação \& Realidade, Porto Alegre, v. 43, n. 2, p. 727-746, abr./jun. 2018. Disponível em: http:// www.scielo.br/scielo.php?script=sci_arttext\&pid=S2175-62362018000200727\&lng=p t\&nrm=iso. Acesso em: 3 jun. 2019. https://doi.org/10.1590/2175-623668737

MATTOS, C.L. G. Estudos etnográficos da educação: revisão de tendências no Brasil. In: MATTOS, C. L. G.; CASTRO, P. A. (orgs.). Etnografia e educação: conceitos e usos. Campina Grande: EDUEPB, 2011. p. 25-48.

ONU - Organização das Nações Unidas. Convenção sobre os Direitos da Criança. Nova York: ONU, 1989.

PERCY-SMITH, B.; MALONE, K. Making children's participation in neighbourhood settings relevant to the everyday lives of young people. PLA Notes, London, n. 42, p. 18-22, out. 2001.

PRADO, R. L. C. A participação de crianças em pesquisas brasileiras das ciências sociais e humanas. 2014. 300 f. Tese (Doutorado em Psicologia Escolar e do Desenvolvimento Humano) - Instituto de Psicologia, Universidade de São Paulo, São Paulo, 2014.

PROUT, A The future of childhood. London: Routledge Falmer, 2005.

ROBERTS, H. Listening to children: and hearing them. In: CHRISTENSEN, P.; JAMES, A. Research with children: perspectives and practices, 40. London: Falmer Press, 2000. p. 142-159.

SANTANA, J. P.; FERNANDES, N. Pesquisas participativas com crianças em situação de risco e vulnerabilidade: possibilidades e limites. In: CONGRESSO LUSOAFRO-BRASILEIRO DE CIENNCIAS SOCIAIS, 11., 2011. Salvador. Anais [...]. Salvador, 7-10 ago. 2011. p. 1-16. Disponível em: http://repositorium.sdum.uminho. pt/bitstream/1822/15479/1/PESQUISAS\%20PARTICIPATIVAS\%20COM\%20 CRIAN\%c3\%87AS.pdf. Acesso em: 23 mar. 2020.

SARMENTO, M. J.; MARCHI, R. C. Radicalização da infância na segunda modernidade: para uma sociologia da infância crítica. Configurações, Braga, n. 4, p. 91-113, 2008. https://doi.org/10.4000/configuracoes.498

SPYROU, S. The limits of children's voices: from authenticity to critical, reflexive representation. Childhood, Thousand Oaks, v. 18, n. 2, p. 151-165, 2011. https://doi. org/10.1177/0907568210387834

TOSTA, S. Os usos da etnografia na pesquisa educacional. In: REUNIÃO BRASILEIRA DE ANTROPOLOGIA, 26., 2008, Porto Seguro. Anais [...]. Porto Seguro: ABA, 1-4 jun. 2008. p. 1-14. 


\section{SOBRE AS AUTORAS}

Natalia Fernandes é doutora em estudos da criança pela Universidade do Minho (Portugal). Professora da mesma instituição.

E-mail: natfs@ie.uminho.pt

Rita de CÁssia Marchi é doutora em sociologia política pela Universidade Federal de Santa Catarina (UFSC). Professora da Universidade Regional de Blumenau (FURB).

E-mail: atoseditora@gmail.com

Recebido em 4 de junho de 2019

Aprovado em 9 de dezembro de 2019 